УДК 339.924

DOI: 10.28995/2073-6304-2019-4-78-91

Методологический подход

к оценке эффективности

экономической интеграции

стран-членов СНГ

Татьяна И. Кузьмина

Российский экономический университет имени Г.В. Плеханова, Москва, Россия, Kиzтіпа.TI@rea.ru

Наталья П. Савина

Российский экономический университет имени Г.В. Плеханова, Москва, Россия, Savina.NP@rea.ru

Аннотащия. Статья основана на анализе существующих научно-методологических подходов к реализации направлений формирования интеграционного потенциала и оценке экономической эффективности интеграционных объединений, представленных в трудах зарубежных и отечественных авторов, а также в отчетах и докладах международных организаций. Проведенное исследование позволило установить, что предлагаемые методики не удовлетворяют потребностям всесторонней и комплексной оценки эффективности интеграции, а выводы, получаемые на их основе, могут показывать разнонаправленные результаты. Было доказано, что темпы роста внутри интеграционной торговли превышают темпы роста торговли стран-участниц СНГ с третьими странами, т. е. эффекта отклонения торговли не наблюдается. Предложен алгоритм проведения оценки экономической эффективности интеграции на примере Содружества Независимых Государств с использованием системы оценки показателей.

Ключевые слова: союзные государства, коэффициент эффективности интеграции, оценка торговых эффектов, система оценки показателей интеграции

Для иитирования: Кузвмина Т.И., Савина Н.П. Методологический подход к оценке эффективности экономической интеграции стран-членов СНГ // Вестник РГГУ. Серия «Экономика. Управление. Право». 2019. № 4. C. 78-91. DOI: 10.28995/2073-6304-2019-4-78-91

(C) Кузьмина Т.И., Савина Н.П., 2019

Статья подготовлена в рамках выполнения НИР на тему: «Разработка методологии расширения торгово-экономического взаимодействия со странами-участницами Содружества Независимых Государств (СНГ) в условиях антироссийских санкций». Приказ № 944 от 25.06.2019.

ISSN 2073-6304 • RSUH/RGGU Bulletin: “Economics. Management. Law” Series, 2019. no. 4 


\title{
Methodological approach to evaluating the effectiveness of economic integration of CIS member states
}

\author{
Tatiana I. Kuzmina \\ Plekhanov Russian University of Economics; Stremyanny lane 36, \\ Moscow, 117997, Russia, Kuzmina.T1@rea.ru \\ Natalia P. Savina \\ Plekhanov Russian University of Economics; Stremyanny lane 36, \\ Mоsсог, 117997, Russia, Savina.NP@rea.ru
}

\begin{abstract}
This article is based on the analysis of existing scientific and methodological approaches to the ways of forming the integration potential and to the assessment of the economic efficiency ofthe integration associations presented in the works of foreign and Russian authors, as well as in the accounts and reports of international organizations. The study made it possible to establish that the proposed methods do not satisfy the needs of a comprehensive and integrated assessment of the effectiveness of integration, and the conclusions drown on their basis can show mixed results. It was proved that the growth rate within the integration trade exceeds the growth rate of trade of the CIS countries with third countries, i.e. there is no effect of the trade diversion. An algorithm is proposed for assessing the economic efficiency of integration using the example of the Commonwealth of Independent States using a performance evaluation system.

Keywords: Union states, integration efficiency coefficient, assessment of trade effects, system for assessing integration indicators

For citation: Kuzmina, T.I. and Savina, N.P. (2019), "Methodological approach to the evaluation of the efficiency of economic integration of the CIS member states", RSUH/RGGU Bulletin. "Economics. Management. Law" Series, no. 4, pp. 78-91, DOI: 10.28995/2073-6304-2019-4-78-91
\end{abstract}

Современные международные экономические отношения характеризуются ростом числа интеграционных объединений и региональных соглашений, а также расширением круга их участников и спектра решаемых проблем. В основе этих процессов, с одной стороны, происходит усиление взаимосвязей и взаимозависимости стран, а с другой - усиливается неравенство в доходах между странами. Более того, одни интеграционные объединения успешно развиваются не одно десятилетие, другие (как на Африканском континенте) продолжают существовать только на бумаге. Поэтому проблемы, связанные с исследованием методологических подходов к оценке эффективности экономической интеграции государствучастников объединений и формирования механизма повышения эффекта их взаимодействия, продолжают оставаться актуальными. 
Значительная роль в разработке методологических подходов к определению критериев экономической интеграции и оценке интеграционных эффектов принадлежит международным экономическим организациям: Всемирному банку (Доклады о мировом развитии), Всемирной торговой организации (Отчеты о мировой торговле), Организации экономического сотрудничества и развития (ОЭСР) (Проекты «Региональная интеграция: наблюдаемые торговые и другие экономические последствия»), Конференции ООН по торговле и развитию (ЮНКТАД) (Ежегодные доклады о торговле и развитии) и др.

Подходы к оценке и анализу эффектов и последствий интеграции в разрезе конкретных региональных интеграционных объединений представлены в работах российских и зарубежных авторов. Существенный вклад в исследование интеграционных процессов на постсоветском пространстве внес авторский коллектив кафедры мировой экономики «Российского экономического университета им. Г.В. Плеханова» под руководством члена-корреспондента РАН Р.И. Хасбулатова [Хасбулатов 2015].

Однако наиболее признанными теориями по оценке экономических эффектов интеграции являются теории Джекоба Вайнера и британского экономиста Дж. Мида, которые могут быть применимы к Таможенному союзу (ТC) Содружества Независимых Государств (СНГ).

В качестве основных эффектов интеграции Дж. Вайнер выделяет, во-первых, переориентацию торговли и, во-вторых, эффект отклонения торговли. Он полагал, что основной целью Таможенного союза и главным результатом (положительным или отрицательным) его функционирования может стать изменение источников поставки товаров [Viner 1937]. По мнению автора, если в результате создания Таможенного союза спросом со стороны стран-участниц пользуются товары, произведенные с наименьшими издержками за пределами TC, то можно считать, что Таможенный союз движется к фритредерству и не возникает эффекта отклонения торговли. В случае реализации протекционистской политики странами-участницами ТС с использованием высоких ставок ввозных таможенных пошлин, более дешевые импортные товары ограничены в доступе на внутренний рынок и возникает спрос на продукцию, произведенную с большими издержками в странах-членах союза. В результате возникает эффект отклонения торговли, который выражается в сокращении объема доходов стран-членов от ввозных таможенных пошлин, что негативно сказывается на благосостоянии населения ТС.

Проанализируем данные эффекты на примере СНГ в период 2000-2018 гг. [Moiseev, Demenko, Savina 2019]. В таблице 1 представлены данные о динамике внешней торговли внутри интеграционного объединения и с третьими странами. 
Методологический подход к оценке эффективности...

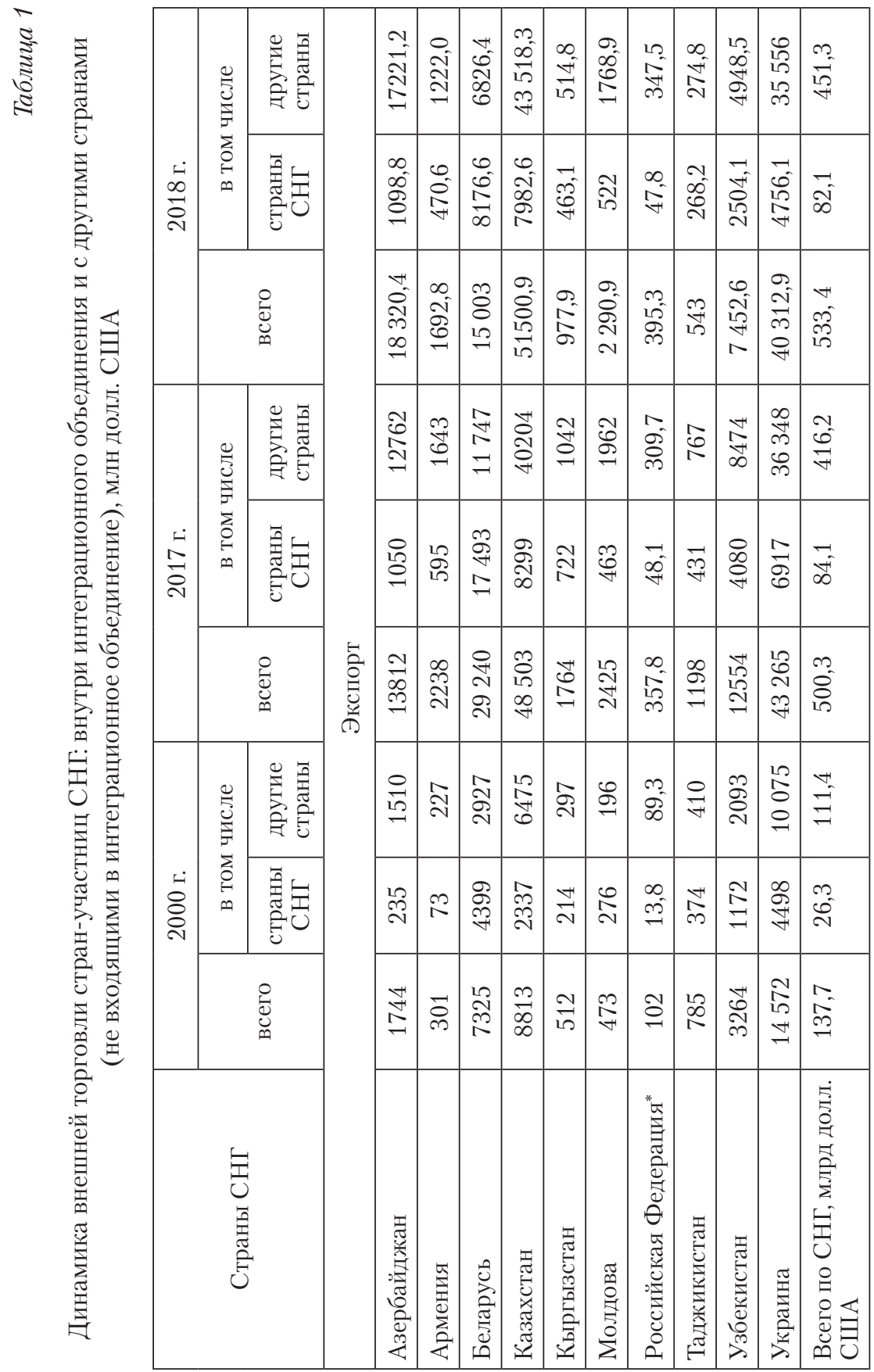




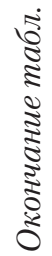

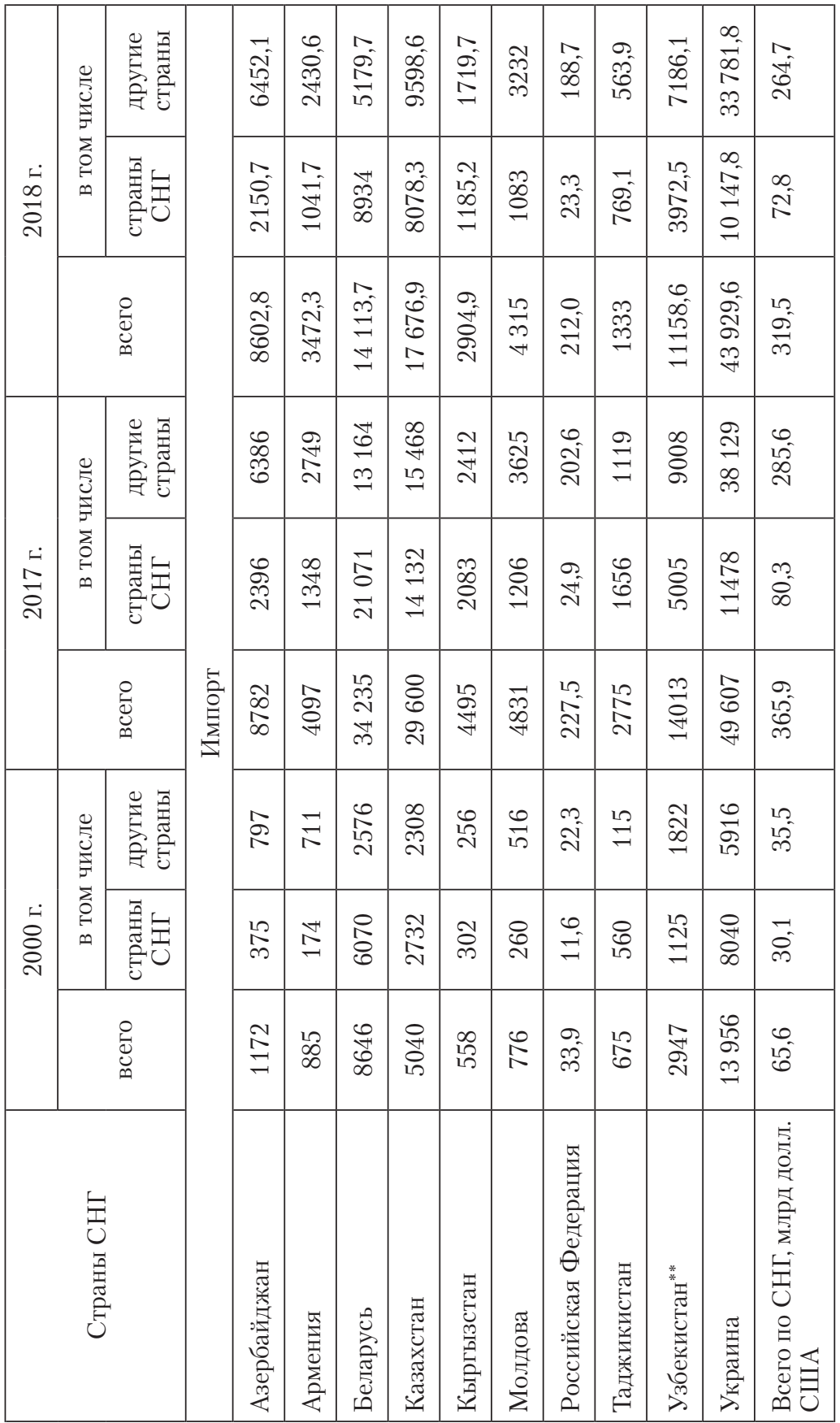


Методологический подход к оценке эффективности...

\begin{tabular}{|c|c|c|c|c|c|c|c|c|c|c|c|}
\hline \multirow{10}{*}{ 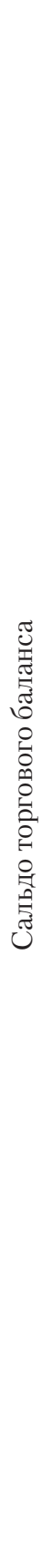 } & $\begin{array}{l}\vec{\rho} \\
0 \\
0 \\
0\end{array}$ & 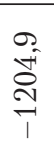 & $\begin{array}{l}r \\
0 \\
0 \\
0\end{array}$ & $\begin{array}{l}\hat{\sigma} \\
\vec{\sigma} \\
\dot{\omega}\end{array}$ & 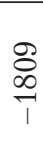 & $\begin{array}{l}\overrightarrow{8} \\
\stackrel{+}{+} \\
\stackrel{1}{1}\end{array}$ & $\begin{array}{l}\infty \\
\infty \\
10 \\
1\end{array}$ & $\begin{array}{l}\vec{j} \\
\stackrel{\infty}{N} \\
1\end{array}$ & $\begin{array}{l}0 \\
\stackrel{N}{N} \\
\stackrel{N}{N}\end{array}$ & $\begin{array}{l}\stackrel{N}{\mathbb{N}} \\
\stackrel{N}{\beth}\end{array}$ & $\begin{array}{l}0 \\
0 \\
\infty\end{array}$ \\
\hline & $\stackrel{\text { ำ }}{\stackrel{0}{1}}$ & $\stackrel{\overrightarrow{1}}{\overrightarrow{1}}$ & $\stackrel{+}{\stackrel{N}{2}}$ & $\hat{\mathrm{S}}$ & $\underset{\text { ○े }}{\stackrel{1}{\circ}}$ & 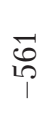 & $\stackrel{1 \Omega}{\stackrel{1}{N}}$ & $\begin{array}{l}0 \\
8 \\
0 \\
1 \\
1\end{array}$ & $\stackrel{\infty}{\stackrel{\infty}{1}}$ & त) & $\stackrel{n}{\stackrel{n}{N}}$ \\
\hline & $\frac{0}{N}$ & $\frac{12}{N}$ & $\begin{array}{l}m \\
\infty \\
\infty\end{array}$ & $\begin{array}{l}\stackrel{\not H}{\sim} \\
\infty \\
m \\
m\end{array}$ & $\stackrel{\widehat{N}}{\stackrel{\Xi}{\top}}$ & 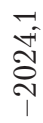 & $\begin{array}{l}m \\
\Re^{\infty}\end{array}$ & 용 & 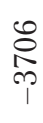 & $\begin{array}{l}\sqrt{0} \\
-1 \\
0 \\
0\end{array}$ & $\stackrel{\stackrel{\rho}{~}}{\stackrel{m}{\sim}}$ \\
\hline & 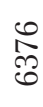 & 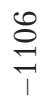 & $\underset{I}{\stackrel{ }{Z}}$ & $\begin{array}{l}\stackrel{\infty}{\infty} \\
\stackrel{+}{v}\end{array}$ & 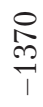 & $\underset{1}{\overparen{\jmath}}$ & $\stackrel{-}{5}$ & กิ & ֶై & $\underset{r}{\stackrel{\infty}{ }}$ & $\begin{array}{l}0 \\
\stackrel{-}{\circ} \\
=\end{array}$ \\
\hline & 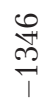 & 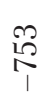 & 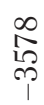 & $\begin{array}{l}\text { m } \\
\infty \\
\infty \\
1\end{array}$ & 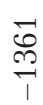 & $\underset{1}{\stackrel{\Re}{+}}$ & $\stackrel{N}{\tilde{N}}$ & 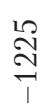 & $\stackrel{12}{\Omega}$ & 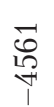 & $\stackrel{\infty}{\infty}$ \\
\hline & $\begin{array}{r}\text { గి } \\
\text { Oे }\end{array}$ & $\begin{array}{l}\infty \\
\stackrel{2}{\rho} \\
\infty \\
i\end{array}$ & $\underset{1}{\stackrel{\sim}{S}}$ & $\begin{array}{l}m \\
\delta \\
\infty \\
\infty\end{array}$ & $\underset{\sim}{\stackrel{N}{N}}$ & 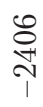 & $\begin{array}{r}m \\
\stackrel{m}{\sim}\end{array}$ & $\stackrel{N}{N}$ & 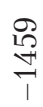 & $\begin{array}{l}\text { Fै } \\
\text { రु }\end{array}$ & $\stackrel{+}{\stackrel{H}{*}}$ \\
\hline & $\stackrel{m}{\Gamma}$ & $\stackrel{+\infty}{\stackrel{+}{+}}$ & $\overrightarrow{\mathrm{n}}$ & 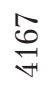 & $\nexists$ & ึิ & $\frac{0}{6}$ & $\stackrel{\overbrace{}}{\mathscr{N}}$ & $\underset{N}{N}$ & $\stackrel{\Omega}{i]}$ & $\begin{array}{l}\stackrel{2}{10} \\
10\end{array}$ \\
\hline & 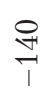 & $\underset{1}{\overrightarrow{0}}$ & $\underset{1}{\pi}$ & م) & $\infty$ & 0 & ชิ & $\stackrel{\infty}{\longleftarrow}$ & $\underset{\forall}{*}$ & 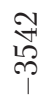 & $\infty_{i}^{\infty}$ \\
\hline & $\stackrel{\Re}{\stackrel{2}{1}}$ & $\begin{array}{l}0 \\
\infty \\
1 \\
1\end{array}$ & 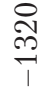 & $\underset{\infty}{N}$ & $\underset{+}{*}$ & ஓ্ণ & $\stackrel{v}{\delta}$ & $\stackrel{g}{\circ}$ & $\stackrel{\infty}{m}$ & $\bar{\sigma}$ & $\vec{i}$ \\
\hline & 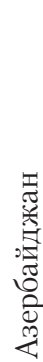 & 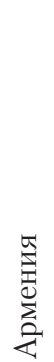 & 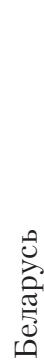 & 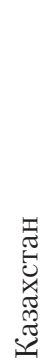 & 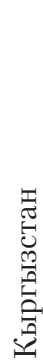 & 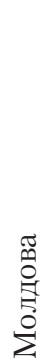 & 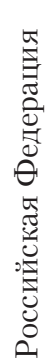 & 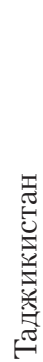 & 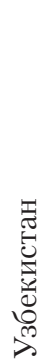 & 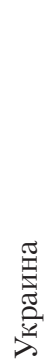 & 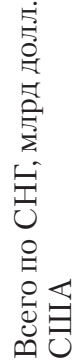 \\
\hline
\end{tabular}

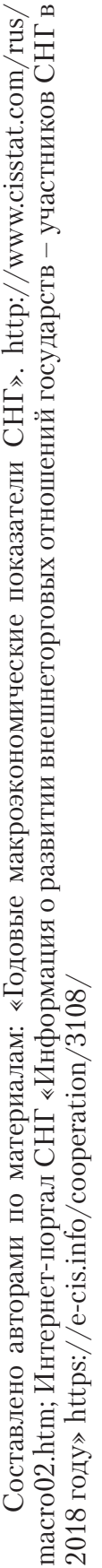


Анализ данных, представленных в табл. 1, показывает что за рассматриваемый период наблюдается значительное (428\%) увеличение объемов экспорта стран Содружества Независимых Государств в третьи страны, и снижение на 76,9\% импорта, при этом сальдо торгового баланса демонстрирует рост на 143,3\%. Если сравнить аналогичные показатели с динамикой взаимной торговли стран-участниц СНГ, то рост объемов экспорта за анализируемый период увеличился на $324 \%$, а импорта - на 266,4\%. При этом если рассматривать по отдельным странам-членам СНГ, то зависимость от внутриинтеграционной торговли в 2018 г. наблюдается только: по экспорту у Беларуси (58\%), Кыргызстана (42\%), Армении и Таджикистана (26\%); по импорту у Беларуси (61\%), Таджикистана (49\%), Кыргызстана, Казахстана (46\%) и 11\% - у России. Полученные результаты свидетельствуют о том, что темпы роста внутриинтеграционной торговли превышают темпы роста торговли стран-участниц СНГ с третьими странами. Следовательно, эффекта отклонения торговли не наблюдается. И в соответствии с теорией Дж. Вайнера, в деятельности СНГ очевидны положительные последствия создания Таможенного союза (ТC).

Ответить на вопрос Дж. Вайнера «Как соотнести потери и выгоду, возникающие в результате создания таможенного союза» пытался и британский экономист Дж. Мид ${ }^{1}$ в своей работе «Trade and Welfare» [Мид 1955]. По мнению автора, отмена пошлин внутри таможенного союза «может отвлечь» страны, входящие в его состав, от дешевого иностранного импорта и приведет к расширению объемов взаимной торговли. Если рассматривать этот эффект Дж. Мида применительно к СНГ, то несмотря на отмену пошлин на ряд товарных групп в странах-членах Содружества ${ }^{2}$, процесса «отвлечения» стран-участниц от внешней торговли со странами, не входящими в TC, не происходит. Наоборот, исследуя динамику экспорта и импорта стран-участниц СНГ с третьими странами с 2000 г. по 2018 г., представленную на рисунках 1 и 2, можно утверждать о наличии сформировавшейся тенденции на ослабление внешнеторгового взаимодействия стран-членов Содружества внутри ТС и усилении этого взаимодействия со странами, не входящими в Таможенный союз [Навроцкая, Сопилко, Ковальчук 2015].

${ }^{1}$ Английский экономист, лауреат Нобелевской премии 1977 г. «За первопроходческий вклад в теорию международной торговли и международного движения капитала». Член Британской академии, иностранный член Национальной академии наук США.

${ }^{2}$ Страны СНГ договорились об отмене пошлин. См.: https://www.zakon. kz/178682-strany-sng-dogovorilis-ob-otmene-poshlin.html

ISSN 2073-6304 • RSUH/RGGU Bulletin: “Economics. Management. Law” Series, 2019. no. 4 


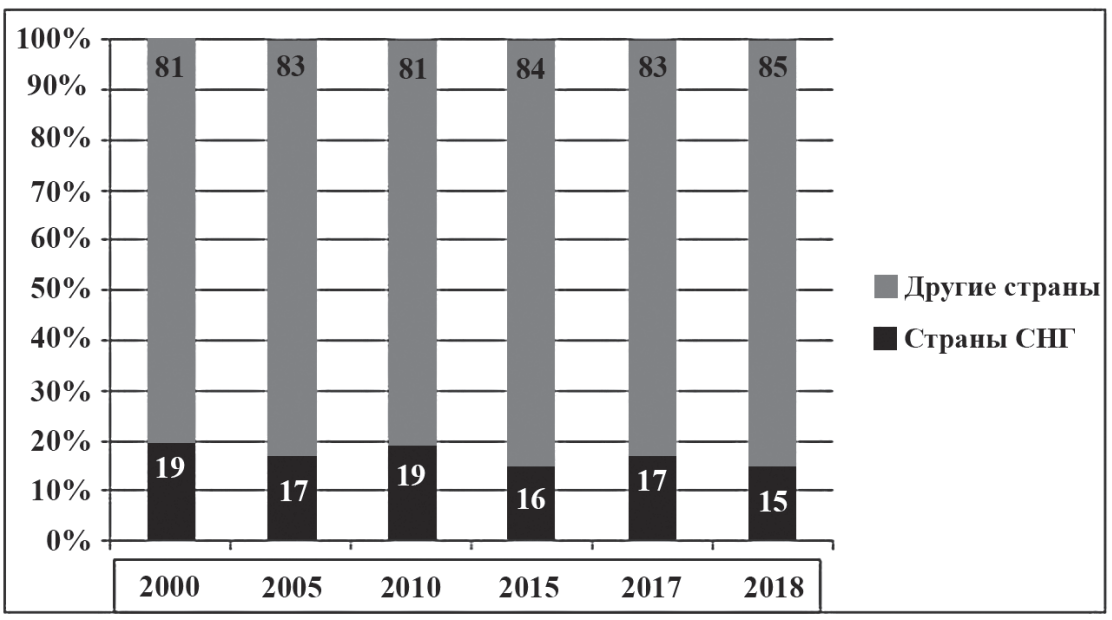

Puc. 1. Доля стран СНГ и других стран мира (не входящих в интеграционное объединение) в общем объеме импорта отдельных стран Содружества, \%

Составлено авторами по материалам: «Годовые макроэкономические показатели СНГ»: http://www.cisstat.com/rus/macro02.htm

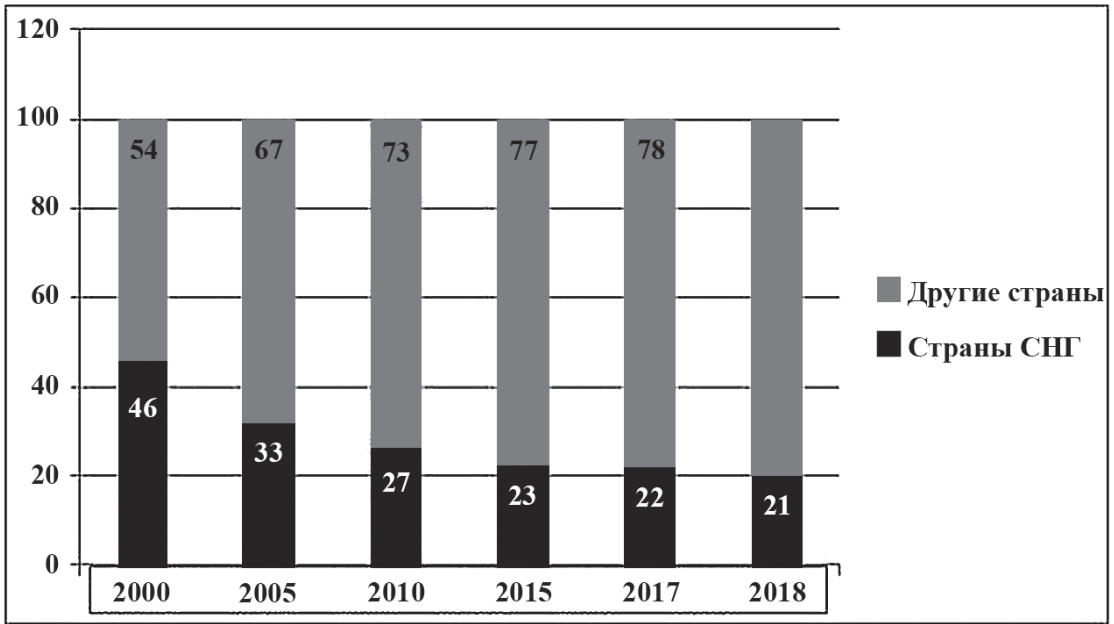

Рис. 2. Доля стран СНГ и других стран мира (не входящих в состав интеграционного объединения) в общем объеме импорта отдельных стран Содружества, \% Составлено авторами по материалам: «Годовые макроэкономические показатели СНГ»: http://www.cisstat.com/rus/macro02.htm 
Рассмотренные подходы к оценке эффективности экономической интеграции противоречивы и в большей мере ориентированы на оценку торговых эффектов, возникающих вследствие отмены или снижения таможенных пошлин внутри интеграционной группировки и связанных с этим изменений издержек производства [Сопилко 2015; Малинина 2009].

Однако интеграция стран Содружества в настоящее время охватывает не только сферу торгового и таможенно-тарифного регулирования, но и ряд других сфер. Например, на основе опыта ЕАЭС по созданию единого цифрового пространства [Кузьмина 2018]. В СНГ стартовал проект создания единого инновационного пространства Содружества ${ }^{3}$ [Demenko, Savina, 2019]. Первым успешно решаемым этапом реализации проекта является интеграции национальных систем НТИ (научно-технической информации) в единое информационное пространство ${ }^{4}$.

Значимыми для углубления интеграционных процессов являются мероприятия по усилению устойчивости валютно-финансовой сферы государств-участников СНГ и снижения рисков в валютно-финансовой сфере стран Содружества, «...последовательно вводятся единые требования к банковскому капиталу, совершенствуются подходы банковского надзора, что обеспечивает сбалансированное управление банковскими рисками и системами внутреннего банковского контроля» ${ }^{5}$. Следует отметить, что для оптимизации расходов на осуществление банковского надзора активно используются опыт ЦБ России по автоматизации бизнес-процессов надзорной деятельности. Другой инициативой Банка России является организация электронного обмена информацией с кредитными организациями и другими поднадзорными организациями, что существенно упрощает и ускоряет процесс сбора данных, нивелируя проблемы, связанные с территориальной удаленностью банков [Kobersy, Kuzmina, Ismagilova, Volkova 2016].

Для углубления интеграционных связей существенное значение имеет развитие межрегионального и приграничного сотрудничества стран-членов Содружества, развитие которого основано на

${ }^{3}$ Интернет-портал СНГ. О состоянии электронных информационных ресурсов поддержки инновационной деятельности в государствах - участниках СНГ: https://e-cis.info/cooperation/3210/

${ }^{4}$ Интернет-портал СНГ «О ходе реализации Соглашения о сотрудничестве в сфере межгосударственного обмена научно-технической информацией от 30 мая 2014 года» https://e-cis.info/cooperation/3210/

${ }^{5}$ О регулятивных режимах в сфере банковского регулирования и надзора в государствах-участниках СНГ В 2018-2019 годах // Интернет-портал СНГ [Электронный ресурс]. URL: https://e-cis.info/cooperation/3079/

ISSN 2073-6304 • RSUH/RGGU Bulletin: “Economics. Management. Law” Series, 2019. no. 4 
исторически сложившихся социально-экономических связях регионов стран СНГ, природно-ресурсное и социально-экономическое размещение территорий и т. п. [Подбиралина 2016] ${ }^{6}$. Все реализуемые в рамках Содружества мероприятия и проекты оказывают влияние на экономическое развитие стран-участниц (табл. 2).

Результаты анализа динамики ВВП Содружества Независимых Государств за анализируемый период (с 2010 по 2018 г.) показывают положительную динамику (увеличение на 135,1\%). Одновременно все страны Содружества демонстрируют положительную динамику ВВП, за исключением Армении, Беларуси, Казахстана

Таблица 2

Динамика экономического развития стран-участниц СНГ, \%

\begin{tabular}{|c|c|c|c|c|c|c|}
\hline \multirow{3}{*}{$\begin{array}{c}\text { Страны - члены } \\
\text { Содружества Независимых } \\
\text { Государств }\end{array}$} & \multicolumn{6}{|c|}{ Значение показателя ВВП } \\
\hline & \multicolumn{3}{|c|}{ к предыдущему году } & \multicolumn{3}{|c|}{ к 2010 г. } \\
\hline & 2016 & 2017 & 2018 & 2016 & 2017 & 2018 \\
\hline Республика Армения & 99,8 & 107,2 & 105,0 & 111,0 & 119,0 & 121,0 \\
\hline Республика Азербайджан & 96,9 & 100,7 & 104,8 & 101,2 & 101,9 & 106,7 \\
\hline Республика Беларусь & 97,5 & 102,4 & 103,0 & 103,4 & 105,9 & 108,9 \\
\hline Республика Казахстан & 99,6 & 102,6 & 102,7 & 127,0 & 129,2 & 131,9 \\
\hline Республика Кыргызстан & 102,4 & 102,6 & 101,6 & 132,4 & 135,0 & 136,6 \\
\hline Республика Молдова & 104,6 & 104,7 & 104,2 & 127,0 & 131,7 & 135,9 \\
\hline Российская Федерация & 99,6 & 101,4 & 102,2 & 103,0 & 104,4 & 106,6 \\
\hline Республика Таджикистан & 104,4 & 104,5 & 104,5 & 150,0 & 154,5 & 159,0 \\
\hline $\begin{array}{l}\text { Республика Туркмени- } \\
\text { стан }\end{array}$ & 104,4 & 107,7 & 104,5 & 175,0 & 182,7 & 187,2 \\
\hline Республика Узбекистан & 104,5 & 103,5 & 103,5 & 159,0 & 162,5 & 166,0 \\
\hline Республика Украина & 103,0 & 103,0 & 103,9 & 91,0 & 94,0 & 97,9 \\
\hline СНГ всего & 101,9 & 103,9 & 103,5 & 127,8 & 131,9 & 135,1 \\
\hline
\end{tabular}

Рассчитано авторами по данным: UNCTADSTAT: https://unctadstat. unctad.org/wds/TableViewer/tableView.aspx; Интернет-портал СНГ. Обзоры социально-экономического развития - https://e-cis.info/cooperation/3208/

${ }^{6}$ Концепция межрегионального и приграничного сотрудничества государств-участников СНГ на период до 2020 года // Единый реестр правовых актов и других документов Содружества Независимых Государств [Электронный ресурс]. URL: http://cis.minsk.by/reestr/ru/index.html\#reestr/view/ text?doc $=5135$ 
и России в 2016 г. по причине негативного влияния экономических санкций со стороны США и ряда европейских стран. Наибольший прирост ВВП в 2018 г. (см. табл. 2) мы видим у Туркменистана и Армении - 107,7 и 107,2\%, соответственно, далее с небольшим отставанием следуют республики Азербайджан $(104,8)$, Молдова $(104,7 \%)$, Таджикистан и Туркменистан $(104,5 \%)$. А замыкает «рейтинг» республика Кыргызстан, где величина роста рассматриваемого показателя в 2018 г. составила 101,6\%. Несмотря на различные темпы прироста ВВП, полученные результаты отражают тот факт, что участие государств-членов СНГ в интеграционном объединении приводит к улучшению их экономического развития и, как следствие, к росту благосостояния населения [Дынкин, Телегина, Халова 2018].

Напрашивается вывод о том, что для повышения объективности и комплексности оценки экономической эффективности интеграции система оценочных индикаторов должна состоять не только из оценки эффективности экономической интеграции Содружества Независимых Государств в целом, но и включать оценку эффективности участия каждого государства в интеграционном объединении [Хасбулатов 2019]. Для комплексной оценки эффективности участия стран Содружества в интеграционном объединении предлагается использовать показатели, всесторонне характеризующие макроэкономическую стабильность государств-членов; экономический рост в странах [Гретченко, Деменко, Савина 2018], а также анализ достигнутого уровня конкурентоспособности национальной экономики как своеобразного индикатора, отражающего степень устойчивости развития всех сфер экономики и качества жизни населения в государстве в сравнении с общемировыми достижениями (табл. 3) [Kuzmina 2017].

Таблица 3

Показатели комплексной оценки экономической эффективности участия стран СНГ в интеграционном объединении

\begin{tabular}{|c|c|}
\hline Направление оценки & Показатели \\
\hline $\begin{array}{l}\text { Макроэкономическая } \\
\text { стабильность }\end{array}$ & $\begin{array}{l}\text { - дефицит консолидированного бюджета сектора } \\
\text { государственного управления; } \\
\text { - долг сектора государственного управления; } \\
\text { - уровень инфляции (индекс потребительских цен) }\end{array}$ \\
\hline Экономический рост & ВВП на душу населения \\
\hline $\begin{array}{l}\text { Конкурентоспособ- } \\
\text { ность национальной } \\
\text { экономики }\end{array}$ & $\begin{array}{l}\text { - Рейтинг страны в «The Global Competitiveness } \\
\text { Report»* } \\
\text { - Рейтинг страны в «Doing Business» }{ }^{* *}\end{array}$ \\
\hline
\end{tabular}

* Ежегодное исследование Всемирного экономического форума, публикуемое в докладе «Отчет о глобальной конкурентоспособности».

** Ежегодное исследование Всемирного Банка, публикуемое в докладе «Ведение бизнеса».

ISSN 2073-6304 • RSUH/RGGU Bulletin: “Economics. Management. Law” Series, 2019. no. 4 
Предлагаемый методологический подход позволяет комплексно подойти к вопросу проведения оценки эффективности экономической интеграции, как с точки зрения достижения экономической интеграции СНГ, так и с позиции экономической целесообразности участия государств-членов интеграционного объединения.

\section{Лuтература}

Гретченко, Деменко, Савина 2018 - Гретченко А.А., Деменко О.Г., Савина Н.П. Оценка готовности экономики России к внедрению цифровых технологий // Плехановский научный бюллетень. 2018. № 2 (14). С. 14-20.

Дынкин, Телегина, Халова 2018 - Дынкин А., Телегина Е., Халова Г. Роль Евразийского экономического союза в формировании большой Евразии // Мировая экономика и международные отношения. 2018. № 4. С. 5-24.

Кузьмина 2018 - Кузьмина Т.И. Проблемы и перспективы формирования цифрового пространства ЕАЭС / / Современная экономика: концепции и модели инновационного развития: IX Междунар. науч.-практ. конф. М.: РЭУ им. Г.В. Плеханова, 2018. С. 341-346.

Малинина 2009 - Малинина E.B. Эффективность национальной политики в условиях финансовой глобализации: валютный аспект // Вестник РГгУ. Серия «Экономика. Управление. Право». 2009. № 3. С. 228-236.

Навроцкая, Сопилко, Ковальчук 2015 - Навроцкая Н.А., Сопилко Н.Ю., Ковальиук М.B. Регионализация в условиях постглобального экономического развития // Вестник РУДН. Серия «Экономика». 2015. № 4. С. 7-15.

Подбиралина 2016 - Подбиралина Г.В. Основные направления внешнеторгового сотрудничества стран Евразийского экономического союза // Международная торговля и торговая политика. 2016. № 1 (5). С. 15-26.

Сопилко 2015 - Сопилко Н.Ю. Производственные связи и региональная интеграция: теоретические аспекты. М.: РУДН, 2015.

Хасбулатов 2015 - Хасбулатов Р.И. Позиции России на новом этапе международной интеграции: Коллективная монография. М.: Ваш формат, 2015.

Хасбулатов 2019 - Хасбулатов Р.И. Международная и континентально-региональные экономические рекомендации: формы, типы, противоречия. М.: РЭУ им. Г.В. Плеханова, 2019.

Demenko, Savina, 2019 - Demenko O.G., Savina N.P. Program for the development of the digital economy: Challenges and prospects // Espacios. 2019. Vol. 40 (Number 25), P. 25.

Kobersy, Kuzmina, Ismagilova, Volkova 2016 - Kobersy I.S., Kuzmina T.I., Ismagilova T.V., Volkova Y.S. The impact of the Global Financial Crisis on Russia's Cooperation with the Countries of EurAsES // International Journal of Economics and Financial Issues. 2016. 6 (SI). P. 300-306.

Kuzmina 2017 - Kuzmina T.I. Current state and prospects of innovative cooperation among the countries members of the EEU // Азимут научных исследований: экономика и управление. 2017. Т. 6. № 4 (21). С. 141-143. 
Кузьмина 2018 - Кузъмина Т.И. Проблемы и перспективы формирования цифрового пространства ЕАЭС // Современная экономика: концепции и модели инновационного развития: IX Междунар. науч.-практ. конф. М.: РЭУ им. Г.В. Плеханова, 2018. С. 341-346.

Meade 1955 - Meade J.E. Trade and Welfare. London: Oxford University Press, 1955. P. $47-49$.

Moiseev, Demenko, Savina 2019 - Moiseev N.A., Demenko O.G., Savina N.P. Computation of reliable interval forecast for dynamic averaging of economic time series regression models // International Journal of Civil Engineering and Technology. 2019. T. 10. № 2. P. 1594-1602.

Viner 1937 - Viner J. Studies in the Theory of International Trade. A.M. Kelley, New York; London: Harper, 1937. P. 129-137.

\section{References}

Demenko, O.G. and Savina, N.P. (2019), "Program for the development of the digital economy: Challenges and prospects”, Espacios, vol. 40, no. 25.

Dynkin, A., Telegina, E. and Khalova, G. (2018), "The role of the Eurasian economic union in the formation of great Eurasia”, World Economy and International Relations, no. 4, pp. 5-24.

Gretchenko, A.A., Demenko, O.G. and Savina, N.P. (2018), “Otsenka gotovnosti ekonomiki Rossii k vnedreniyu tsifrovykh tekhnologii" [Assessment of the readiness of the Russian economy for the introduction of digital technologies], Plekhanorskii nauchnyi byulleten', no. 2 (14), pp. 14-20.

Khasbulatov, R.I. (2015), Pozicii Rossii na novom ètape mezhdunarodnoj integracii: kollektionaya monografiya [Russia's positions at the new stage of international integration], Vash format, Moscow, Russia.

Khasbulatov, R.I. (2019), Mezhdunarodnaya i kontinental'no-regional'nye ekonomicheskie rekomendacii: formy, tipy, protivorechiya [International and Continental-Regional Economic Recommendations: Forms, Types, Contradictions], Plekhanov Russian Economic University, Moscow, Russia.

Kobersy, I.S., Kuzmina, T.I., Ismagilova, T.V. and Volkova, Y.S. (2016), "The Impact of the Global Financial Crisis on Russia's Cooperation with the Countries of EurAsES”, International Journal of Economics and Financial Issues, 6 (SI), pp. 300-306.

Kuz mina, T.I. (2018), "Problemy` i perspektivy` formirovaniya cifrovogo prostranstva EAE`S”, Sovremennaya e konomika: koncepcii i modeli innovacionnogo razvitiya, IX Mezhd. nauch.-prakt. konf. [Problems and prospects of formation of the digital space of the EAEU. Modern economy: concepts and models of innovative development. IX. science-pract. Conf.], Plekhanov Russian Economic University of Economics, Moscow, Russia, pp. 341-346.

Kuzmina, T.I. (2017), "Current state and prospects of innovative cooperation among the countries members of the EEU”, Azimut nauchnykh issledovanii: ekonomika i upravlenie, vol. 6, no. 4 (21), pp. 141-143.

Malinina, E.V. (2009), "The effectiveness of national policies in the context of financial globalization: the currency aspect", RSUH/RGGU BULLETIN. "Economics. Management. Law" Series, no. 3, pp. 228-236. 
Meade, J.E. (1955), Trade and Welfare, Oxford University Press, London.

Moiseev, N.A., Demenko, O.G. and Savina, N.P. (2019), "Computation of reliable interval forecast for dynamic averaging of economic time series regression models", International Journal of Civil Engineering and Technology, vol. 10, no. 2, pp. 1594-1602.

Navrotskaya, N.A., Sopilko N.Yu. and Koval'chuk M.V. (2015), "Regionalizaciya v usloviyah postglobal'nogo ekonomicheskogo razvitiya" [Regionalization in the context of post-global economic development], RUDN BULLETIN. Series Economics, no. 4, pp. 7-15.

Podbiralina, G.V. (2016), "Osnovnye napravleniya vneshnetorgovogo sotrudnichestva stran Evraziiskogo ekonomicheskogo soyuza" [The main directions of foreign trade cooperation of the countries of the Eurasian economic Union], International trade and trade policy, № 1 (5), pp. 15-26.

Sopilko, N.Yu. (2015), Proizvodstvennye soyazi i regional'naya integratsiya: teoreticheskie aspekty [Industrial Relations and Regional Integration: Theoretical Aspects], Peoples' Friendship University of Russia, Moscow, Russia.

Viner, J. (1937), Studies in the Theory of International Trade, Harper, New York, London, pp. 129-137.

\section{Сведения об авторах}

Кузьмина Татьяна И., доктор экономических наук, профессор, Российский экономический университет имени Г.В. Плеханова, Москва, Россия; 117997, Москва, Стремянный пер. 36; Kuzmina.TI@rea.ru

Савина Наталья П., кандидат экономических наук, Российский экономический университет имени Г.В. Плеханова, Москва, Россия; 117997, Москва, Стремянный пер. 36; Savina.NP@rea.ru

\section{Information about the authors}

Kuzmina Tatiana I., Dr. of Sci. (Economics), professor, Plekhanov Russian University of Economics, Moscow, Russia; bld. 36, Stremyanny Lane, Moscow, Russia, 117997; Kuzmina.TI@rea.ru

Savina Natalia P., Cand. of Sci. (Economics), Plekhanov Russian University of Economics, Moscow, Russia; bld. 36, Stremyanny Lane, Moscow, Russia, 117997; Savina.NP@rea.ru 